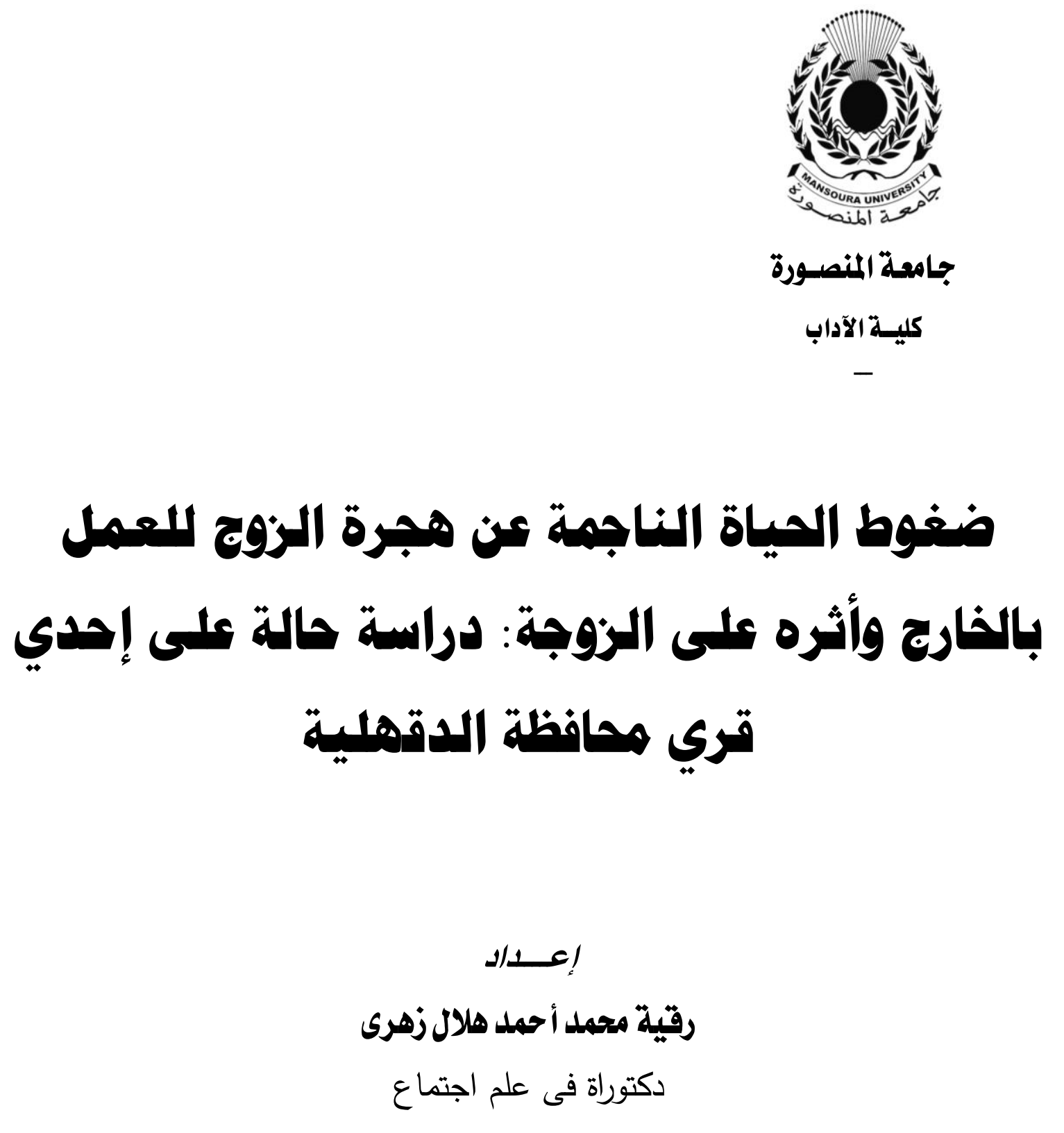

$$
\text { مجــلة كلـــية الآداب - جامعــة المنصــورة }
$$




\section{ضغوط العياة الناجمة عن هجرة الزوج للعمل بالخارج وأثره على الزوجة: دراسة حالة على إحدي قريى محافظة الدقهلية}

\section{رقية محمد أحمد هالال زهرى}

هدفت الدراسة إلى تحديد أنواع الضغوط الحياتية للزوجة الناتجة عن هجر الزوج للعمل بالخارج، والكثشف عن أعراض هذه الضغوط

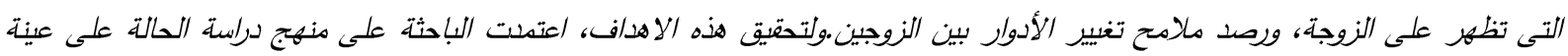

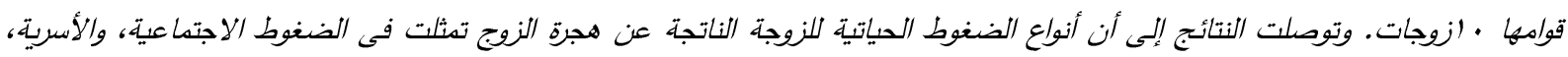

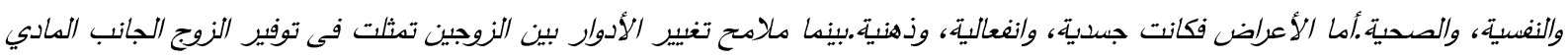

والزوجة فى اتخاذ القرارات، وزيادة المسئوليات، تربية الابناء.

\section{Abstract}

The study aimed to determine the types of life strees of the wife resulting from the migration of the husband to work abroad, and to detect the symptoms of these strees that appear on the wife, and monitor the features of changing roles between spouses. To achieve these goals, the researcher relied on a case study on a sample of 10 wives. That the types of life strees of the wife resulting from the migration of the husband was the social strees, family, psychological, and health. The symptoms were physical, emotional, and mental. While the features of changing roles between the spouses were to provide the husband's material side and wife in making decisions, Yat, raising children

وتعد الهجرة تحولا من التحولات التى

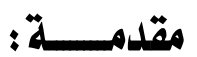

شهدها المجتمع المصري والتى ازدادت فى الآونة الاخيرة وفتحت بابا جديدا للعمل والمكسب المادي لأبناء المجتمع المصري، فقد أثرت هذه الهجرة بشكل كبير وواضح على طبيعة العلاقة والأدوار بين الزوجين، فقد تقلص دور الزوج المهاجر في الأسرة وتغير دور الزوجة التى أصبحت تتحمل على عاتقها العديد من المسئوليات الضخمة التى قد لا تستطيع قدراتها وامكانيتها أن تتحمل هذه

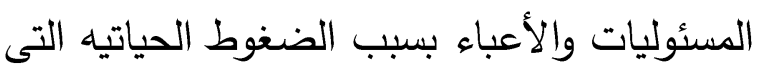
تتعرض لها؛ كالضغوط الاجتماعية مثل التفكك الاسري والعنف الأسرى والخيانة والهجر وضغوط العمل، والضغوط الأسرية؛ خاصة فيما يتعلق بموضوع الانجاب وتدخل أهل الزوج وإقامة أحد الاجداد في نفس البيت أو زيارتهم باستمرار وعدم احترام خصوصيات الزوجة بتدخلهم المتزايد ومحاولة فرض السيطرة وموت أحد الوالدين

تعد الأسرة هي الخلية الأولى في تكوين المجتمع الإنساني والركيزة الأساسية في تشكيل السلوك الإنساني، وذلك لتعدد الوظائف الاجتماعية والتربوية التي تقوم بها كنظام اجتماعي لها، إلا أن قيام الأسرة بهذه الوظائف بالثكل الصحيح في وقتنا الحالي هو أمر غاية في الصعوبة نظرا لمطالب الحياة الحديثة وما تسببه من ضغوط وأزمات نفسية واجتماعية واقتصادية مختلفة، ففي ظل المتغيرات المجتمعية المعاصرة التى تتعرض لها الأسرة، نجد أن الأسرة تمثل انعكاسا لما هو قائم بالمجتمع، حيث تتأثر بمجموعة من التحولات الاقتصادية والسياسية والاجتماعية التى تحدث فيه وما يتواكب مع ذلك تغيير فى الأدوار والعلاقات بين أعضاء الأسرة الواحدة لاسيما الزوجين . 
1-ازدياد نسبة هجرة الأزواج للعمل بالخارج

فى الآونة الأخيرة وهو ما أظهرته عديد

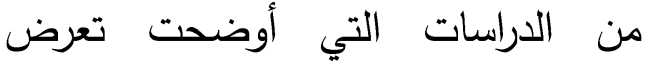

زوجاتهن للعديد من الضغوط التي توضح مدى أهمية وخطورة ذلك على تماسك الأسرة والمجتمع حيث إن أي تهديد لكيان الاسرة هو تهديد لكيان المجتمع ككل. r-تعد أول دراسة اجتماعية، عن الضغوط الحياتية للزوجة الناتجه عن هجرة الزوج للعمل بالخارج، مطبقة على قرية المرساة

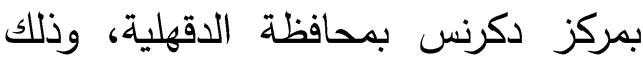
فى حدود علم الباحثة فى مجال

تخصصها.

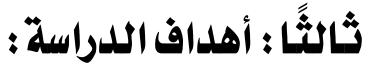

1-تحديد أنواع الضغوط الحياتية للزوجة

الناتجة عن هجرة الزوج للعمل بالخارج. r-الكثف عن أعراض الضغوط الحياتية للزوجة الناتجه عن هجرة الزوج للعمل

$$
\text { بالخارج. - بزوجه }
$$

r- رصد ملامح تغيير الأدوار لكل من

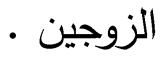

\section{رابعًا : تساؤلات اللدراسة :}

1-ما أنواع الضغوط الحياتية للزوجة الناتجة

عن هجرة الزوج للعمل بالخارج؟ r-ما أعراض الضغوط الحياتية للزوجة الناتجه عن هجرة الزوج للعمل بالخارج؟ r-ما ملامح تغيير الأدوار لكل من الزوجين

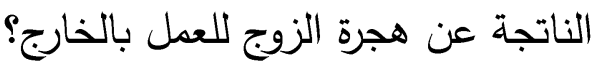

للزوجة وصراعات بين الزوجين، والضغوط النفسية؛ كالإصابة بحالات الاكتئاب والعصبية والتوتر والحرمان النفسي أو العاطفى والقلق الإصابه والخوف، والضغوط الصحية؛ كانخفاض الضغط

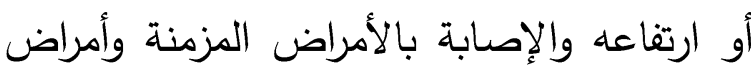
خاصة بالجهاز الهضمي. أولاً: مشكلة الدراسلة: تعد هجرة الأزواج للعمل بالخارج إحدي الظواهر الاجتماعية التى شغلت أذهان الكثير من التراج علماء الاجتماع، حيث إن مصر من بين الدول التى لديها زيادة سكانية، وفائض في العمالة

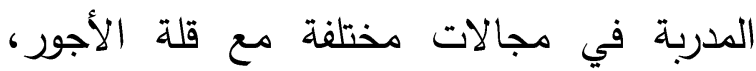

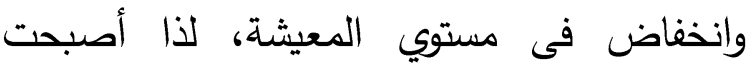
الهجرة لدول الخليج الحل الأمثل لديهج من أجل تحسين مستوي المعيشة، مما نتج عنه العديد من الضغوط الحياتية لزوجاتهن سواء كانت ضغوط اجتماعية أو أسرية أو نفسية أو صحية، والتى لتى لون تظهر فى أعراض متعددة قد تكون جسدية أو أو انفعالية أو ذهنية أو علاقات شخصية نتيجة لتغيير الأدوار لدي كل من الزوجين.

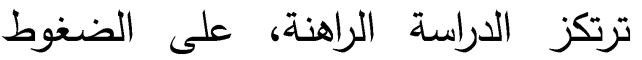
الحياتية للزوجة الناجمة عن هجرة الزوج للعمل

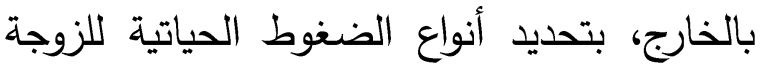

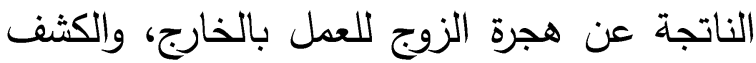

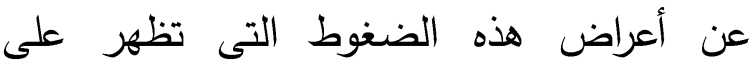
الزوجة، ورصد ملامح تغيير الأدوار بين

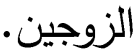

ثانيًا : أهمية الدراسة :

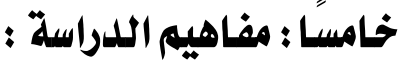


بزيادة أدوارها المتوقعه، مما يسبب لها مشاكل 1-ضغوط الحياة :

تعددت المفاهيم المختلفة حول معني كثيرة.

\section{ب- - هجرة الزوج :}

تعرف الهجرة بأنها هي انتقال الفرد أو الزو الجماعة من مكان إلى آخر بقصد الإقامة الدائمة

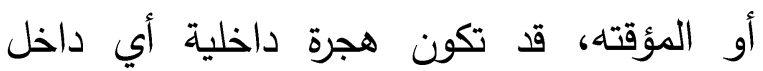
الدولة، إذ ينتقل الفرد من الريف إلى المدينة، أو لونائ

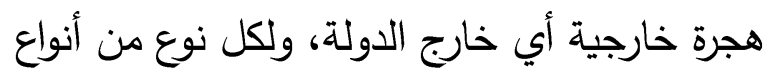

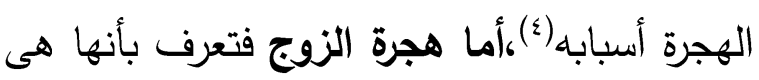

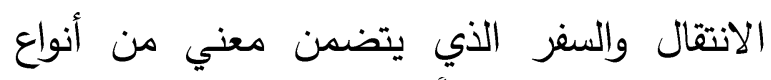
الرحيل الطوعي تحقيقا لرغبة لم تتحقق فى مكان

الموطن (ن)

المفهوم الإجرائي لهجرة الزوج:هي سفر

الزوج لبلد خليجي بقصد إقامة مؤقتة تحقيقا

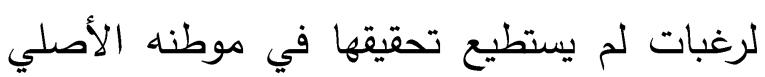

وتحسين مستوي معيشته.

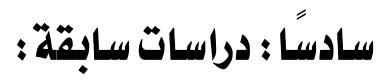

هناك العديد من الدراسات المتصلة متصلة بهجرة الزوج للعمل بالخارخ، ودراسات

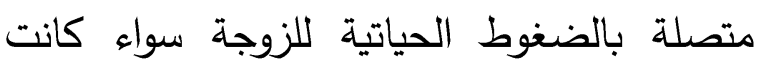

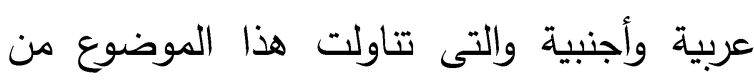
نواحي مختلفة منفصلة، فالدراسات التى تتاولت

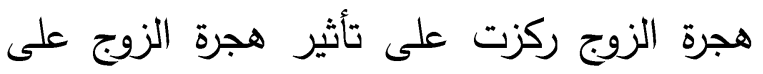
موضوع الانجاب، والآثار السوسيولوجية الناتجة

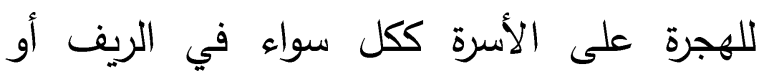

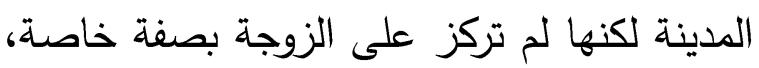
والدراسات التى تتاولت الضغوط الحياتية للزوجة ركزت على الضغوط الحياتية لدي الزوجات العاملات وعلاقتها بالاكتئاب، والضغوط الحياتية
ضغوط الحياة حيث صيغت تعريفات متعددة،

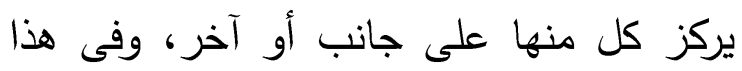

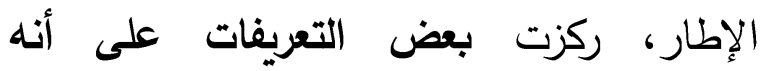
هو "مجموعة من القوي التأثيرية التى تواجهها المرأة

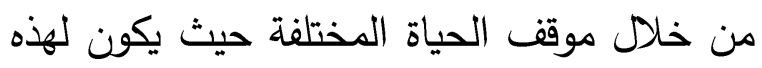
القوي مجموعة من التأثيرات علي الأداء والوظائف

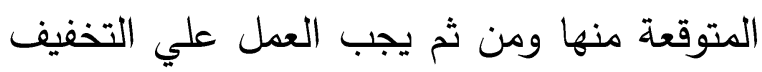

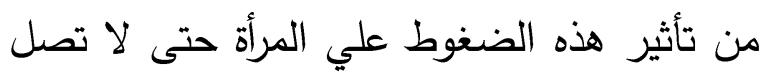

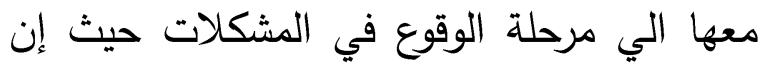
الضغوط ينتج عنها مجموعة من المشكلات (الصحية- - التعليمية والثقافية- الاقتصاديةالاجتماعية)".(")بينما عرفه البعض الآخر على الآله

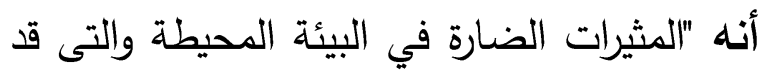
تكون نفسية أو مادية أو اجتماعية أو مؤقته أو أو

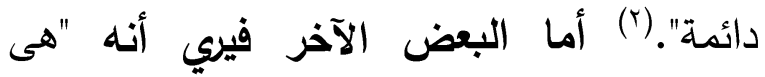
المواقف التى يمر بها الفرد فى حياته ويتصور أنها تفوق امكاناته وموارده الثخصية والبيئية اللازمة للتعامل معها، وبالتالى يعتري الفرد بسبيها

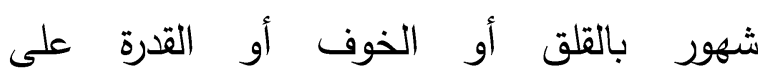
(") السيطرة".

المفهوم الإجرائي لضفوط الجياه :_مجموعة من

المواقف المتعددة التى تمر بالزوجة فى فترة سفر الزوج تؤثر على قيامها بأداء أدوارها ووظائفها

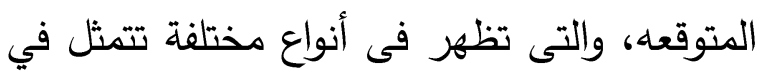

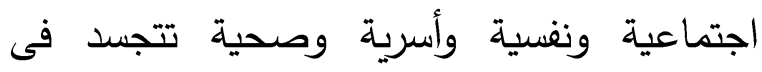
صورة أعراض جسدية أو انفعالية أو معرفية، ونفية ونهية تعاني منها نتيجة لتغير الادوار بينها وبين زوجها 


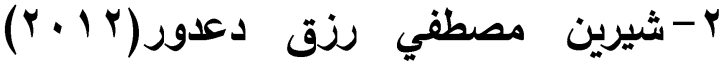
بعنوان: الآثار السوسيولوجية لهجرة الآباء على الأسرة المصرية دراسة ميدانية فى الانى مدينة المنصورة (v) هدفت الدراسة إلى التعرف على أهم دوافع سفر الآباء إلى الخارج، ورصد ملامح التغيرات التى أصابت الأدوار داخل الأسرة المصرية، وإلقاء الضوء على الآثار المصاحبة للهجرة الخارجية على الأسرة المصرية، والكشف عن المشكلات الأسرية الناتجة عن عملية الهجرة الخارجية . واستخدمت الدراسة الميدانية المنهج الوصفي باستخدام عدة أدوات هي الملاحظة والمقابلة وإستمارة الأستبيان على عينة عمديه بلغت(10 (مبحوثة من (زوجات الآباء المهاجرين إلي البلدان النفطية)،في منطقة (توريل وتوريل

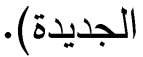

وتوصلت نتائج الدراسة إلى أن الدافع

الأول والأساسي لهجرة أرباب الأسر المصرية إلى الى الى الع الع البلدان النفطية هو العامل المادي، وكما أن العديد من الأمهات الللائى هاجر أزواجهن للخارج يعانوا من تلك الهجرة حيث يتعرضون لمشاكل نفسية وعصبية ويزداد شعورهن بالقلق وقلة إحساسهر

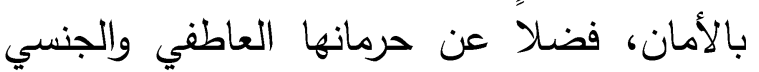
الذي يؤثر بلا شك على صحتها النفسية، وهجرة الأبناء إلى الخارج تظهر أعراض إكلينيكية ونفسية ظاهرة كالاكتئاب والانطوائية والعدوانية، وظهور

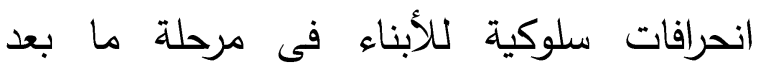
الطفولة، وتعاطى المخدرات وظهور حالات من الأبناء يعانوا من الأدمان، والتطرف الديني.
والدعم الاجتماعي الدقدم لها ولأولادها، ودور شخصيتها والامكانات الاجتماعية في مواجهة ضغوط الحياة، والصلابة والمساندة الاجتماعي كمتغيرات ملطفة لأثر ضغوط الحياة، ولم يتطرق

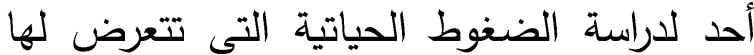
الزوجة الناتجة عن هجرة الزوج للعمل بالخارج. واستفادت الباحثة - في دراستها الراهنةمن جميع هذه الدراسات، والتى تمثل أساسيات

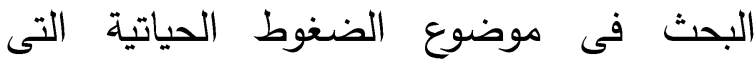
تتعرض لها الزوجة الناتجة عن هجرة الزوج للعمل بالخارج. أولاً :دراسات متصلة بهجرة الزوج للعمل بـالخارخ:

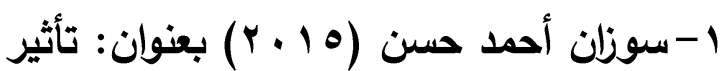
الهجرة على مستويات الإنجاب (دراسة

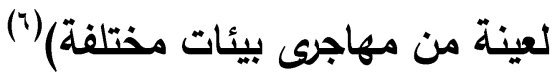
هدفت الدراسة إلي تحديد معامل الهجرة الخارجية المؤقتة، وتحديد معامل للهجرة اعتمادا

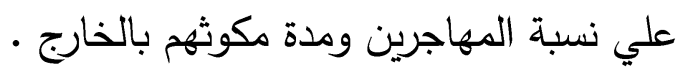
استخدمت الدراسة الوصفية باستخدام أسلوب المسح الاجتماعي بالعينة على عينة قوامها 110 من زوجات المهاجرين فى قرية القبابات محافظة الجيزة. وتوصلت الدراسة الي أن العوامل المؤثرة على الإنجاب هي العوامل الإقتصادية والاجتماعية، وأن تأثير عامل الهجرة يصل إلى الى الى خفض فى الإنجاب مقداره r\&\% وبهذا تصبح نسبة الإنخفاض في الإنجاب بسبب إضافة عامل الهجرة (عدد الأبناء الذي تم تجنبه نتيجة للهجرة) . \%V1.7 هو 
بلد المهر، وأن هجرة رب الأسرة تؤدي إلى مجلى حدوث خلل فى عملية التتشئة الاجتماعية للأبناء وانخفاض فى مستوى التحصيل الدراسى لهم،

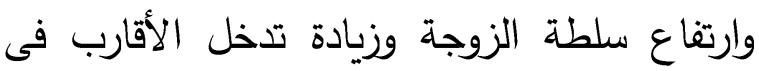
الشئون الأسرية، وحدوث المشكلات الأسرية .

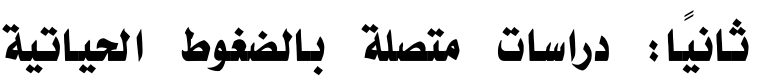

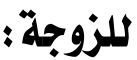

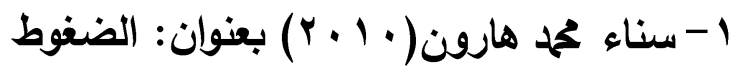
الحياتية لاي الزوجات العاملات وعلاقتها

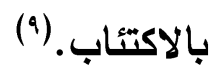

هدفت الدراسة إلي التعرف على سمة الضغوط الحياتية لدي النساء العاملات بمدينة

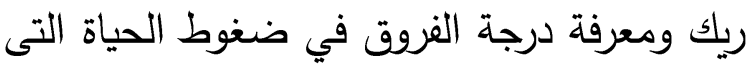
تعزي لكل من الحالة الاجتماعية والعمر ومعرفة العلاقة بين الضغوط الحياتية والمستوي التعليمي وكذلك العلاقة بين الضغوط الحياتية والاكتئاب

النفسي.

استخدمت الدراسة المنهج الوصفي

واعتمدت على عدة أدوات هي استمارة الاستبيان ومقياس للاكتئاب ومقياس مواقف الحياة الضاغطة، على عينة قوامها ... من من النساء المتزوجات العاملات بمدينة ريك بالسودان. وتوصلت لعدة نتائج أبرزها: أن النساء تعانى من ارتفاع في الضغوط الحياتية، وأنه توجد فروق ذات دلالة احصائية للضغوط الحياتية تعزي لمتغير الحالة الاجتماعية ومتغير العمر، وأنه توجد علاقة ارتباطية بين درجات الضغوط لإنيات

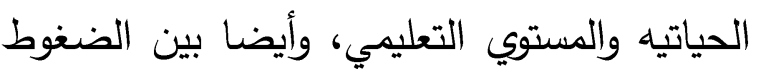

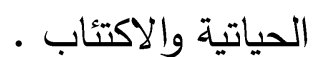

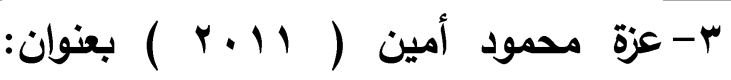
الهجرة الخارجية وأثرها على الأسرة للريفيين (دراسة ميدانية لعينة من الأسر

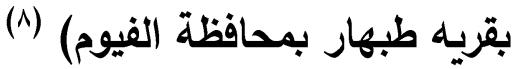
هدفت هذه الدراسة إلى التعرف على خصائص المهاجرين الريفيين، وأهم عوامل الطرد

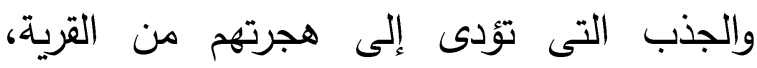
وأنماط الهجرة، والآثار الاجتماعية والاقتصادية الإيجابية والسلبية لهذه الهجرة بالنسبة للأسرة

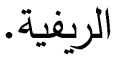

واستعانت الباحثة بالمنهج المقارن بطريقة

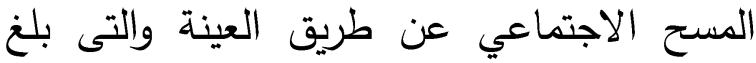
قوامها وغير المهاجرين بقرية طبهار بمحافظة الفيوم، وذلك من خلال استخدام عدة أدوات، كاستمارة المقابلة، والملاحظة المباشرة، وتحليل الوثائق والسجلات، والاستعانة بالإخباريين. وتوصلت الدراسة الى عده نتائج أبرزها:

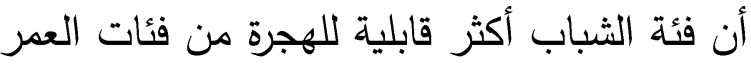
الأخرى، وأن الأجور المنخفضة ومشكلة البطالة فى القرية من أهم عوامل الطرد التى تؤدى إلى الى التى الهجرة الخارجية، ورجود شبكة العلاقات الاجتماعية من الأقارب والأصدقاء والجيران فى ودى الثى بلد المهجر من أهم عوامل الجذب التى تؤدى إلى الى الى التي الهجرة الخارجية، وأن نمط الهجرة المؤقتة الثرعية

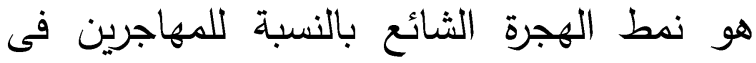
القرية الزراعية، وأن شبكة العلاقات الاجتماعية المرتكزة على الأقارب والدعارف لها دور فى لهى الهي مساعدة المهاجرين على التغلب على العقبات فى لهى 
الدعم والمساندة من أسرهم ومشرفيهم فى العمل لمواجهة الضغوط التى تواجههم . عonald ganellen and pual عراسة blanty الاجتماعي كمتغيرات ملطفة لأثر ضغوط لعانه

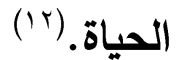

هدفت الدراسة إلى معرفة العلاقة بين المساندة الاجتماعية والصلابة ومعرفة أيهما يلعب لهبه دورا أكثر أهمية فى تخفيف أثر ضغوط الحياة، وتوصلت إلى أنه توجد علاقة ارتباطية موجبة دالة بين الصلابة والمساندة الاجتماعية وبين تخفيف حدة الضغوط الحياتية، وأن المساندة والصلابة النفسية من تعد من العوامل المخففة من أثر الضغوط الحياتية خلال تفاعلهم معها. سابعًا : المنهج وأدوات البحثث: اعتمدت الباحثة في بحثها الراهن على منهج دراسة الحالة بوصفه منهجا مناسبا، لطبيعة الدراسة، وأهدافها وتساؤلاتها، وتم هذا من خلال

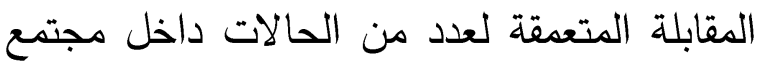
الدراسة، وأداة الملاحظة المباشرة أثناء الدراسة داستة الميدانية بهدف جمع بيانات يصعب عليها عن طريق تطبيق دليل دراسة الحالة من خلال المقابلة وغيرها من الأساليب البحثية الأخرى، وأداة

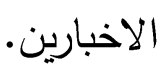

ثامنًا : مجالات الدراسة. الدان. اـ المجال الجغرافي: اختارت الباحثة إجراء الدراسة فى قرية المرساة بمركز دكرنس التابعة لمحافظة الدقهلية. وذلك لعدة أسباب:
(2004) keith Stephanie دراسة بعنوان: الضغط والدعم الاجتماعي للأمهات والأطفال. (1.)

هدفت الدراسة إلي تحديد مستوي الضغوط للأمهات والاطفال، وتوصلت الدراسة إلي أن هناك عكسية بين الضغط علي الأم وبين الدعم الاجتماعي،وكنلك أوضحت أن الأمهات يواجهن مستويات مختلفة من الضغوط بسبب

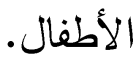

Suzanne quellete kabasa ب-دراسة بعنوان: دور الثخصية والامكانات الاجتماعية فى مواجهة ضغوط (11). الحياة

هدفت الدراسة إلى معرفة العلاقة بين الثخصية والمصادر الاجتماعية وإدراك المساندة الاجتماعية كمتغيرات وسيطة في مواجهة الضغوط الحياتية.

وتم تطبيق الدراسة على • مفردة من V V العاملين المتزوجين، واستعان الباحث باختبار الأحداث الضاغطة واختبار الصلابة النفسية

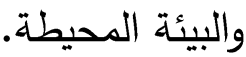

وتوصلت الدراسة إلى أن العمل من أهم

مصادر ضغوط الحياة وخاصة عند العاملين المتزوجين ولديهج مسئوليات متعددة، وينتج الضغط داخل العمل عند تغيير مسئوليات العمل

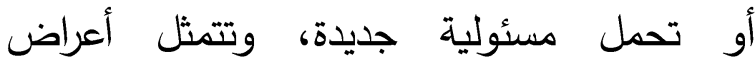
الضغوط فى ضغوط نفسية، وضغوط أسرية

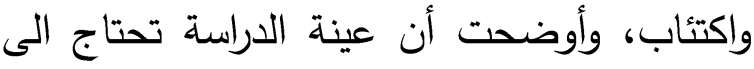


نفس المشكلة، وتوطدت صداقة الباحثة

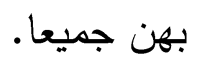

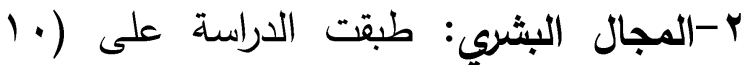
حالات من الزوجات اللاتي هاجر أزواجهن للعمل

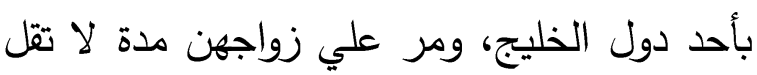
عن r سنوات) r-المجال الزمني: استغرقت الدراسة الميدانية ثلاثة أشهر من بداية شهر مارس حتي نهاية شهر مايو.

تاسعًا : النتائج التحليلية للدراسة الميلدانية: تضمنت الدراسة الميدانية البيانات الأساسية والخصائص الديموجرافية للمبحوثات، وأنواع الضغوط الحياتية للزوجة الناتجة عن هجرة الزوج، وأعراض هذه الضغوط، وملامح التغيير

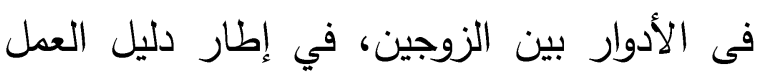

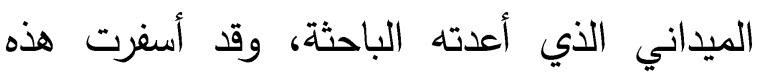
الدراسة عن التالى:

أولاً: البيانات الأساسية والخصائص الديموجرافية للمبحوثات: 1- التركيب العمري: أوضــــت نتــائج الدراســة الميدانيــة أن الأزواج عمـرهم يقـع في الثلاثينيـات والأربعينيـات والخمسينيات، لكنه يرتفع في أواخر الثلاثينيات وذلك الكالك

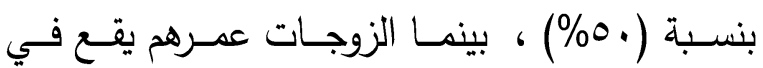

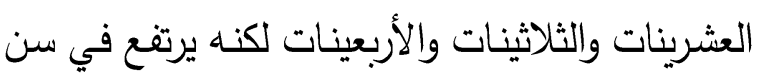
الثلاثينيات وذلك بنسبة (،^\%\%). ولاحظت الباحثة أن الفارق العمري بين الزوجين فى • 9\% من الحالات لايقل عن عشر سنوات.
- قرب هذه القرية إلى حد ما من الباحثة، ووجود بعض التسهيلات التي تيسر لين البالها مشقة الانتقال والعمل الميداني. وقد

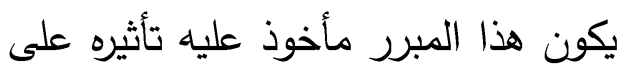

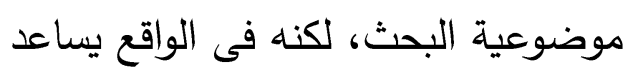
الباحثة على تلافي مشكلات سير الدراسة ودقتها من أبرزها ما يخص تلافئه الوقت والجهد. - تعد قرية المرساه من أكثر القري بمحافظة الدقهلية التي ينتشر بها ظاهرة

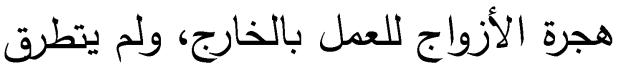
الباحثين لدراسة هذه الظاهرة من قبل.

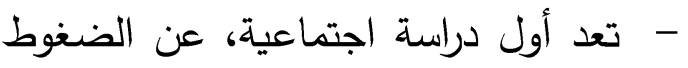
الحياتية للزوجة الناتجة عن هجرة الزوج للعمل بالخارج، مطبقة على قرية المرساة

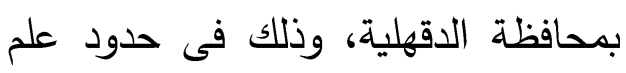
الباحثة فى مجال تخصصها. - خبرة الباحثة، كمشرفة لطلاب المعهد العالي الخدمة الاجتماعية بالمنصورة، فى البالهابه بعض الجمعيات ومكاتب التوجيه والاستشارت الأسرية التي تعمل على حل

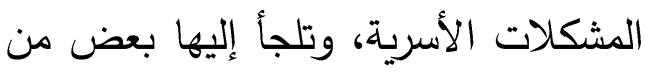

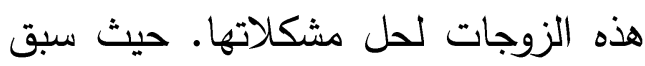

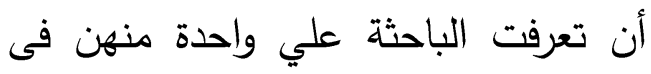
مكتب توجيه واستثارات أسرية، كانت تلجأ

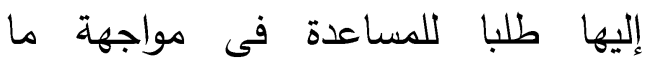
تتعرض له من ضغوط بسبب المشكلات الأسرية، وما إن توثقت علاقة الباحثة بها، حتى قدمت إليها معارفها، ممن يعانين من 


$$
7
$$

تشـير نتـائج الدراســة الميدانيـة أن الفئسة

الأكبر مـن المبحوثات ممـن لديهن أبنـاء وذلك لك

بنسبة (•V\%) يليهم الذين ليس لديهم أبناء بنسبة

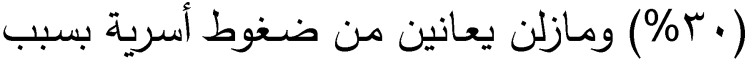

عدم الانجاب ومحاولة تدخل أهل الزوج.

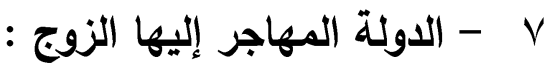

تثير نتائج الدراسة إلى أن الفئة الأكبر

هاجرن الى دولة دبي بالامارات بنسبة(·؟\%\%)

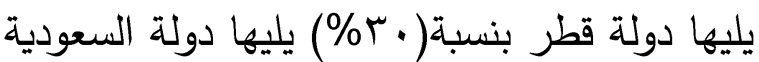

$$
\text { بنسبة ( . (1\%). }
$$

ثانيًا أنواع الضفوط الجياتية للزوجة الناتجة

\section{عز هجرة الزوج للعمل بـالخارج:}

كثـــت الدراســة الميدانيــة عـن أنــواع

الضغوط الحياتية للزوجة الناتجة عن هجرة الزوج

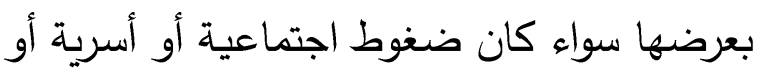

نفسية أو صحية:

1- الضغوط الاجتماعية:

أظهرت الدراسة الميدانية أن الغالبية

العظمى من الزوجات تعانين من العنف بجميع

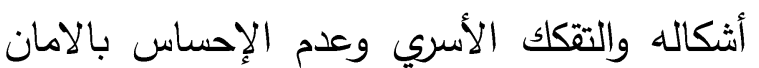
والخيانة الزوجية وضغوط العمل، وعبرت العديد من حالات الدراسة الميدانية على ذلك، وفسرت أحد الزوجات تعرض الأسرة لتفكك الاسري وعدام احساسها بالأمان بقولها " إن العلاقات بينتا اضطربت حتى وصلت لمرحلة رفع دعوى طلاق في مرة ، أنا للأسف معتش حاسة بالأمان معاه"، وسردت زوجة ثانية "بيوصلني كثير لمرحلة

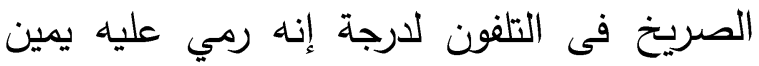

r- الحالة التعليمية:

أشـارت نتائج الدراســة الميدانيـة أن الفئسة

الأكبر كانت من الأزواج الذين يحملون مؤهلات عليا وذلك بنسبة (•٪\%)، أما الزوجات أيضا كانت من الذين يحملون مؤهلات عليا وذلك بنسبة (.^\%)

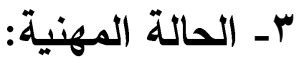

أوضـــت البيانـات الأساسـية فيهـا أن

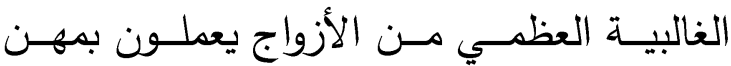

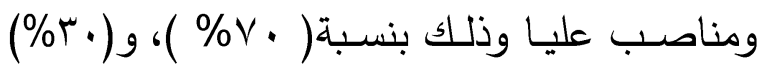
بمناصب ومهن متوسطة لكنها ذات رواتب مجزية ـ أما الزوجات فكانت أعلى نسبة بين اللاتي يعملن وذلك

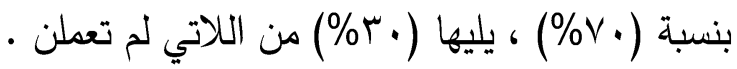

$$
\text { צ- السكن: }
$$

تشـير نتـائج الدراسـة الميدانيـة أن هـولاء

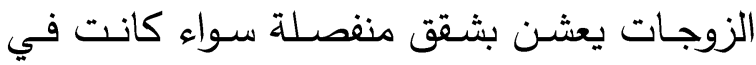

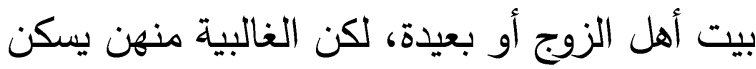

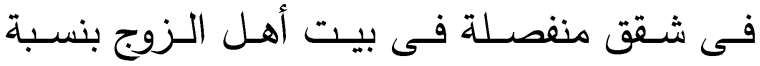
( أمـا الباقي يعشن بعيدا عن بيت أهل الزوج، كما يعد السكن في شقق منفصلة في بيت أهل

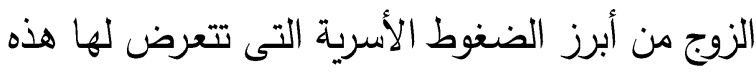
الزوجات، حيث إن هذا السكن شكلى فالمعيشة كاملة تكون في بيت أهل الزوج والذي يرجع ذلك لمدي تسلط حموات هذه القرية واستبدادهم وتحكمهم المفرط. 0 - عدات سنوات الزواج:

أجمعت حسالات الدراسـة على أن عـد الند

سنوات زواجهم تتراوح مـا بين ع سنوات ل ع كال

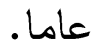


الطلاق مرتين"، وعبرت زوجة ثالثة بقولها"أنا وتقول زوجة الزوبة أخرى مشيرة لتعرضها للعنف

الاقتصادي والنفسي"ساعات كثير بنتشاكل بسبب

الفلوس عاوز يديني ... Pن جنيه مصروف البيت

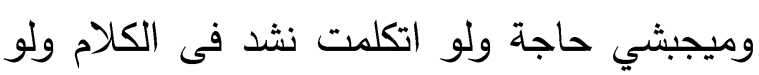

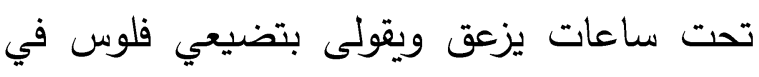

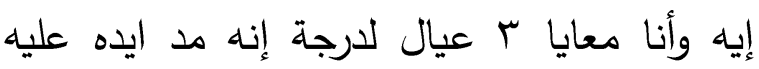

قولتله إنته بني آدم بخيل ومعفن، الناس مفكره إننا

عايشين ياما هنا ياما هناك، وهو مضيق كل حاجة عليه يجيب لأهله بس إنما أنا وولاده

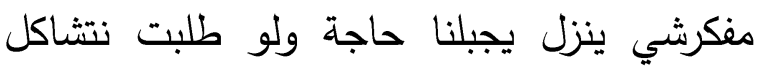
ويشتم"، وعبرت أخرى على الرغم من قدرته لئه المادية وارتياحه المادي الكبير إلا أنه يمارس هن

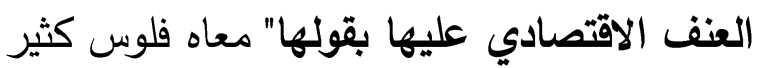

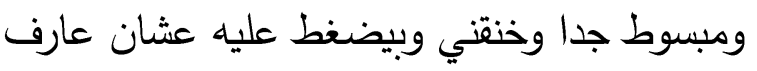

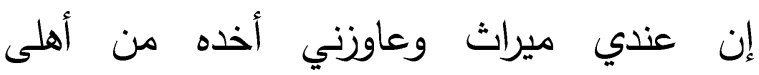
ومبيرضاش يبعتلى فلوس عاوزني أجيبه ويكتبه

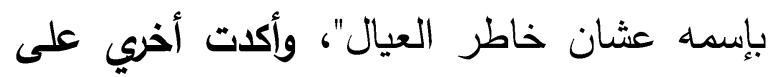
تعرضها لهذا النوع من العنف بقولها " أنا جوزي اخي علي

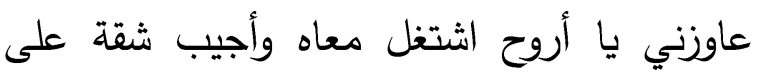

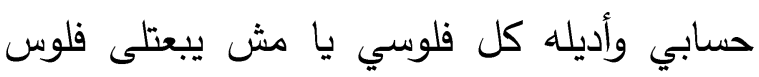
عارف إن وظيفتي بره بتجيب فلوس كثير وفعلاً مبيرضاش يبعتلى شيء واضطر إن أروح أخد من أهلى واسلتف وساعات أدي دروس أو أربي طيور إضئ عشان أجيب أي دخل".

وتحكي أخرى تعرضها للعنف الجنسي

بقولها "كثير بيخاصمني لما بينزل وساعات يهجرني فى أوضة النوم وينام فى أوضة وأنا فى لئل

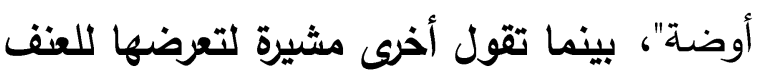

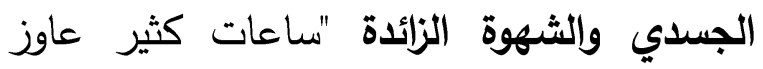

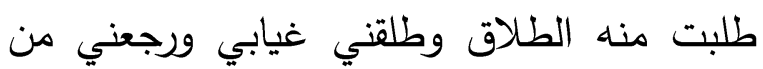
غير معرف غصب عني" وكثفت الدراسة الميانية أيضا استخدام الأزواج ضد الزوجات العنف بجميع أثكاله، حيث سردت أحد الزوجات موضحة تعرضها لزوجات للعنف الجسدي والنفسي بقولها" أنا جوزي ايديه ثقيلة لما بينزل ويتعصب عليه بسبب أمه لما تقوله حاجة بينزل فيه تلطيش لما آخر مرة كسر لئل

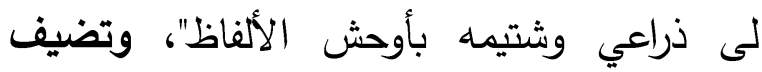
زوجة ثانية تعرضها للعنف النفسي " أنا من كثر الضغوط اللى بشوفها كثير بسبب أهله وهو كمان بيجي عليه على الرغم إنه عارف إنهم وحثين في لئي حقي ومبهدليني وكل واحد حواليه بره يجي يكلمني يفكر إني واحدة بقي جوزها مش معاها وسهل إنه يوصلها وأتحايل عليه ينزل مفيش بقيت أقوله طلقني كل شوية من كثر الأرف اللى حساه حاسة ولهايل

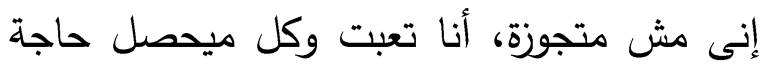
ويحطني تحت ضغط نفسي من غير سبب بقيت أطلب منه الطلاق كثير"، وتقول زوجة ثالثة من فئل عشان مش قعدين مع بعض وعلى طول مسافر ديما بنثد قصد بعض لدرجة إننا عدنا بنشتم وتحكي زوجة رابعة "بيقعد يضايق فيه عشان أسافر له ويشتم ويعمل حاجات كثيرة ويستفني وأنا معتش عارفة أخد أجازات من ونات شغلي"، وتضيف أخرى " أقل حاجة لما بينزل

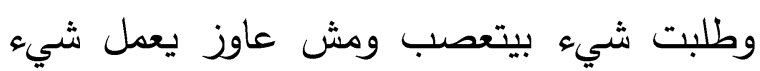
ويتطاول بالكلام وانتي وانتي وشتيمة وقلة أدب"، بعلى وشئ 
اليوم وأرجع البيت أشيل مسئوليته لوحدي من تربية ولادي ومسئوليتهم لشغل البيت لحماتي اللى لى لئي مبتريحشي نفسها ومطلوب مني أكلم جوزي وأدلعه ياما يبقي فيه مشاكل بينا"، وتحكي زوجة ثانية "أيوة برجع كثير من شغلي تعبانة ومرهقة وبقعد

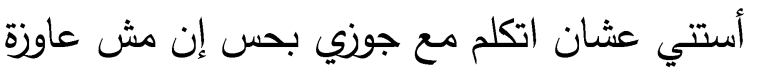
أطول فى أوقات كثيرة فى الكلام من كثر المشاكل لأن أهله كل شوية بيشحنوه مبتتكلمي مبتعملشي مبتجيش لأني قاعده في بيت أهلى"، وتقول زوجة

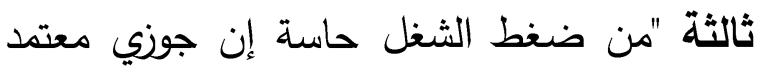
على مرتبي على الرغم إنه مسافر ده بيخليني مضغوط نفسيا"

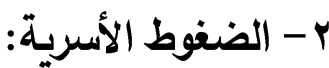
عكست الدراسة الميدانية أنواع الضغوط الأسرية التى تعرضت لها الزوجه، حيث تمثلت في عدم الانجاب وما تتعرض له من جانب أهل الزوج، وتؤكد أحد الزوجات على ذلك بقولها: " أنا بسمع كلام كثير كل يوم من عيلة جوزي وأقعد الزد

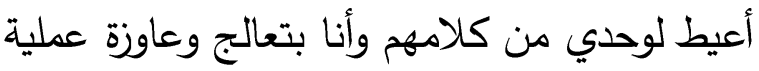

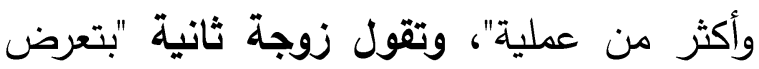

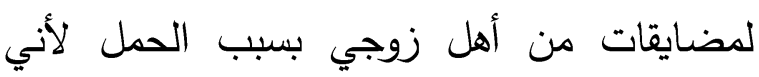
مخلفتش لسه وهيا مصممة إنى أروح أكثف وهيا اللى تاخدني تكثف عليه"، وتقول ثالثة "أنا لسة

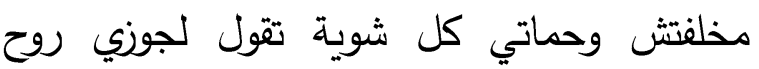
اتجوز واحدة تانية وبتقعد تعايرني وتقولى انا ابني سليم إنتي العيب منك ايه اللى يجبره على العيشة دي مع واحدة مبتخلفي ومش باينلها خلفة، وكمان اخواته البنات وبيعارونى إنى لسه مخلفتش وبيقولى إمال هو متجوز ليه تعالي نروح لاكاترة
علاقة جنسية كثيرة لدرجة إن بتعب وبيطلب

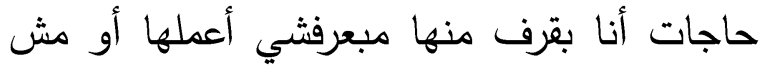

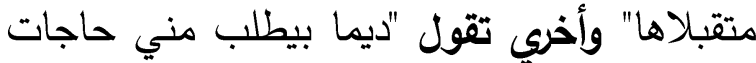

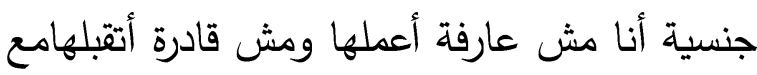
اعرف ان فيه ستات بيعملو كده وبيبقي عنيف لما

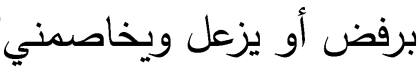

\section{كما أوضحت أحد الزوجات تعرضها} للخيانة الزوجية من قبل زوجها عن طريق الانترنت ومواقع التواصل الاجتماعي بقولها "اكتثفت في يوم بعد نزوله من السفر إنه بيكلم واحدة وبيخبي التلفون في الهدوم في الدولاب عشان مشفوش تلفون صغير جايبه وبالصدفة برتب الدولاب لقيته ولقيتها واحدة بعتاله رسايل وهو بيراسلها ومش بس كده عامل صفحة على لعل الفيس مش باسمه وبيكلمها عليها"، وعبرت أخرى

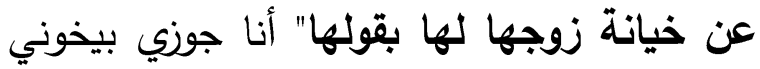
كل يوم كنت بستغرب متغير ليه وبيخوني بيراسل

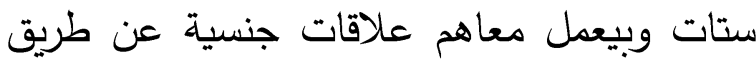

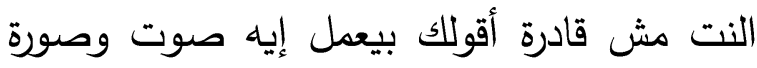
النت ده بجد خراب على بيوت كثيرة وبيسهل أرف كثير وببقي عارفة بس هعمل إيه عاوزة أعيش ولو عرفته إنى عارفة ممكن يعمل أي شيء على حي إئ عيني وولادي هيتبهلو وخاصة إنى أهلى كلهم اتوفو ومليش مكان أروح ولا شغلانه أصرف منها" وكثفت أيضا الدراسة الميدانية عن الدانة تعرض بعض الزوجات للإجهاد اليومي نتيجة لضغوط العمل ومسئولياتها الزوجية، وعبرت أحد لئ لئه

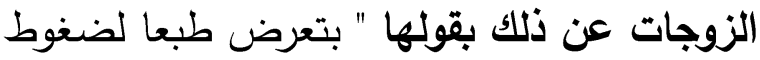
جوه عملى بتعب في شغلي ببقي مجهده طول 
كما لاحظت أن قلة من هؤلاء الزوجات

اللاتي حملن بمجرد الزواج، أما الكثيرات فقضين

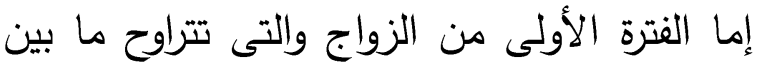
عام إلى خمسة أعوام بحثا عن العلاج، أو لم الماج ينجبن لهذا الوقت على الرغم من عدم وجود لديهن عائق للانجاب سوي عدم وجود الزوج الزاب

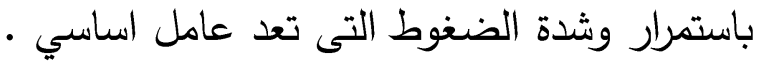

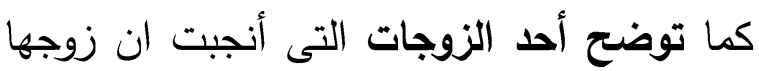
هو السبب فى عدم الانجاب بسبب الدوالى وعند

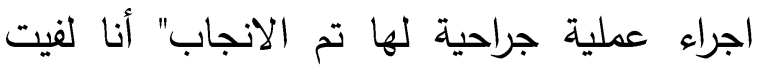
كثير على دكاترة وطلع فى الآخر جوزي عنداه دوالى بمجرد معمل عملية خلفت ثلاث أطفال وكنت مبهدله نفسي والمفروض أي واحدة لازم جوزها يكثف قبلها بدل مبنسع كلام ملوش لازم وبيتخرسو مجرد ميعرفو إن العيب من ابنهم" لئح

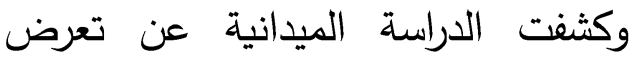
الزوجات للضغوط أيضا من جانب الزوج نفسه أو أهله بسبب انضمام عضو جديد للأسرة كحمل غير مرغوب فيه، وتؤكد أحد الزوجات على ذلك

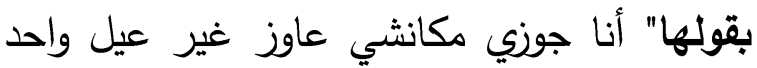
وكل ما أحمل يعمل معايا مشكلة وكل مرة ينزل

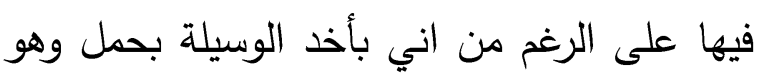
مبيرحمشي نفسه وبيلومني هو ووالدته على كل

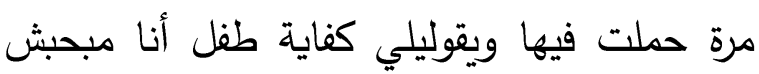

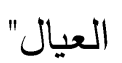

كما أظهرت أيضا عن الضغوط الأسرية التى تتعرض لها الزوجات بسبب اقامة أحد الحد الأجداد في نفس البيت أو زيارتهم لها باستمرار وعدم احترام خصوصيتهم أو انثغال وقتهر لفارته بالترار
ونطمن إنك كويسة على الرغم إن جوزي نبه

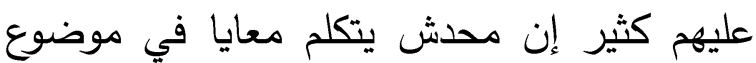

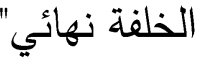

وعبرت بعض المبحوثات الأخريات تعرضهن لهذه الضغوط قبل انجابهن، حيث قالت أحد الزوجات" اتعالجت أربع سنين، بعد ثلاث سنين قلت لجوزي روح اتجوز لما سمعت كلام وحش من حماتي ومن قرايبه ومن كل حد لحد ماتعالجت وعرفت إنى حامل وجبت ولد أول مرة وبنت تاني مرة وكل مرة كنت بلف على الدكاترة"، وتقول زوجة ثانية " حماتي لما عرفت إنى حامل بقت تعاملنى حلو بعد مكانت كل شوية تعايرني"،

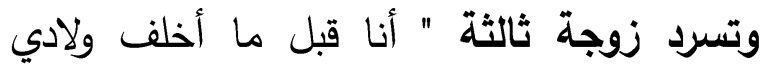
حماتي صمدت تاخدني بعد كلام كنت بسمعه فى لى لـ

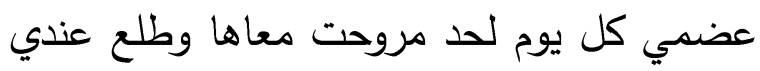
لخبطة في هرمون اللبن ولما خدت علاج واتعالجت منه مع إنه حاجة بسيطة إلا أنها كل شوية تقولى لولايا مكنتيش هتخلفي ولا هتعرفي إنك كنتي تعبانة وهتظلمي ابني معاك لأن العيب كان منك مع إن عدي على الكلام ده سنين ودي حاجة عادية جدا عند أي واحدة ممكن يكون على على دهن

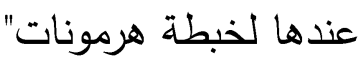
وتعكس هذه الأفعال الموجهة من بعض هونات

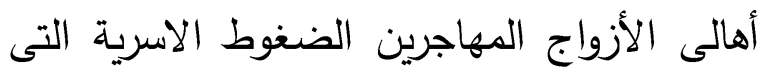
تتعرض لها الزوجات فى حالة سفرهم، حيث الهي استفسرت الباحثة من هؤلاء الزوجات بسؤالها عن

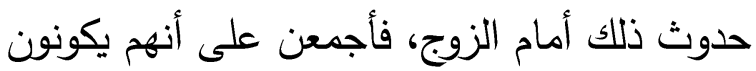

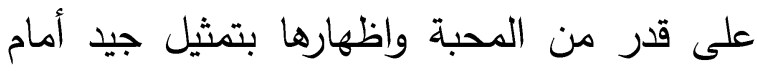

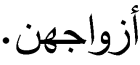


وتحكي أخري"وصلت الدرجة بأهل

زوجي إنهم يجبولى واحد غريب جنسية غير مصرية فى شقتي وأنا قاعدة عند والدي معرفثي فئي شيء تضايفه في شقتي ومن غير استاذان أو احترام لخصوصياتي حتى لما جوزي عرف لفي واعترض حاولت تقنعه هيا وإخواته وعمل معايا

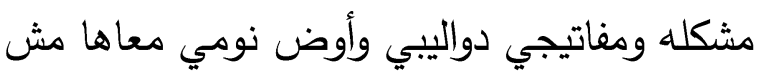
راضية تديهالى"، وتحكي اخري" كل مرة أروح

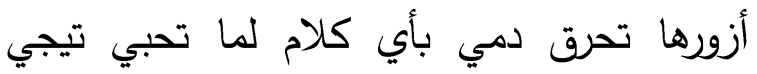

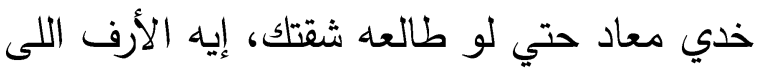
بتجبيه وانتي جايه ده، ومرة رمت فى وشي الحاجات اللى داخلة بيها وأنا راحة أزورها " وأظهرت الدراسة الميدانية أيضا أن موت روتا لأها

أحد الوالدين وخاصة الأب يجعل الزوجة تتعرض التها لضغوط أسرية عديد لعدم وجود من يقف بجانبها فى المشاكل حتي مع زوجها نفسها، حيث يثعر الزوج أن ليس لديها من يساندها فيسيء معاملتها

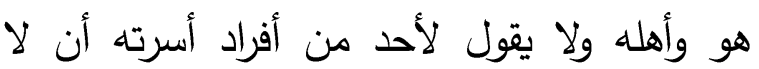

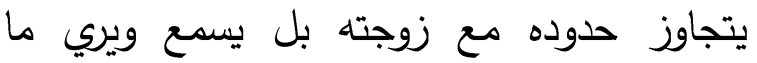

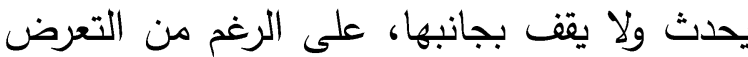
للظلم والافتراء، وعبرت أحد الزوجات عن ذلك بلك الترن بقولها " زوجي كان بيعمل حساب لابويا قبل

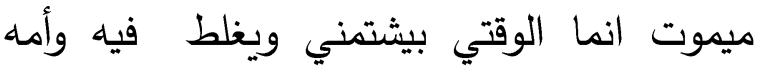
بتعاملنى وحش وتقترى علي قدامه وتهيني وهو

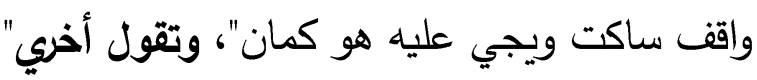
جوزي بيقول معتثي ليكي حد تتسندي عليه هتروحي فين لما تغضبي ابوكي مات واخواتك

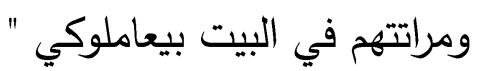

وتدخلهم المتزايد فى حياتهم من أزواجهن ومحاولة فرض السيطرة عليهن، تقول أحد الزوجات " أنا حماتى سايبة عيالها كلها ومبترضاش تقعد الا فى البيت معانا لدرجة إن مبعرفشي أكلم جوزي بليل اطمن عليه معرفشي عنه شيء طول اليوم وهو عاوز يسمع كلام حلو بليل ودي لازقه لو قومت

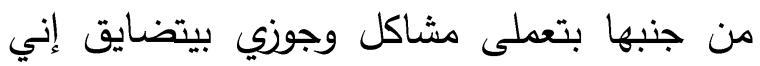
مش بعرف اكلمه وحاولت أفهمه مفيش فايدة وكمان كل شوية عاوزة أكل معين ومفيش حاجة بايته وابنها بيبعتلى فلوس قليلة أوي وبتعملى ومعلى مشاكل لو عملت مرة كثري او بطاطس وجيبالى

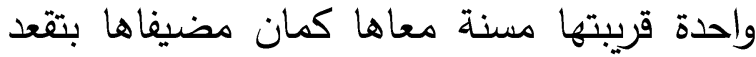
بالثهور كمان عاوزانى أخدمها هيا كمان" وتقول زوجة ثانية" مقعداني فى الثقة معاها طول مجوزي مسافر حتي لما يجي من السفر عوزانى نبات معاها أنا وجوزي وعيالى مش حاسة إن إن متجوزة"، وتقول زوجة ثالثة" كل ما أروح شغلي ماتي

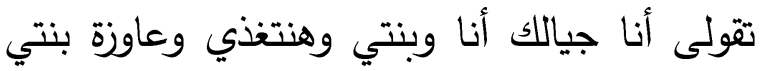

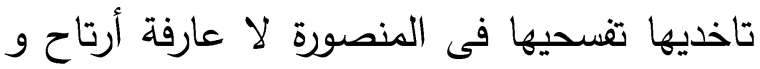
أروح شغلي ولا أحس إن بيتي حد بيحترم خصوصياتي ويستأن قبل ميجي مهما كانت صفته"

وتقول أخري "حماتي بتقولى مش هخليكي

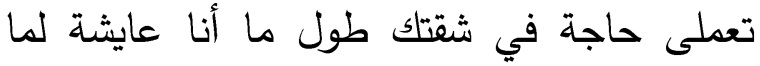
أبقي أموت اعملى اللى انتي عوزاه وكل شيء عاوزة تتدخل فيه"، وتسرد زوجة أخري" حماتي بتطلع تأخد من شقتي كل حاجتى على الرغم إن عندها كل شيء هيا وبناتها وسلايفي". 
ساعات بحس إني دحتاجة لجوزي أحس بوجوده

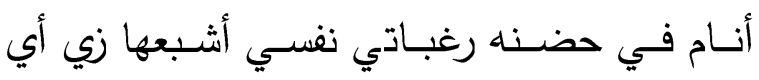

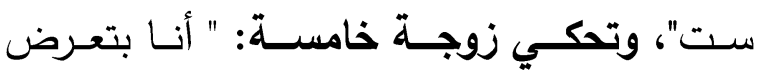
لمواقف محرجة كثيرة بسبب أن جوزي مش موجود

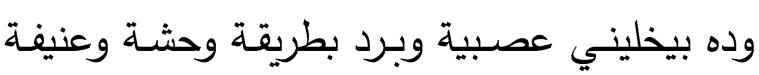
وفيها عصبية شديدة"، وعبرت زوجـة أخري:" أنا حاسة بحرمان شديد عاطفي ناقصني أحس بحنية

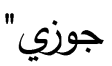

وتسرد زوجة أخرى" عدت حاسة باكتئاب والله بيجي عليه أوقات والله ببقي عاوزة أموت أخت نفي" ، وتقول زوجة أخرى" ناقصني حاجات

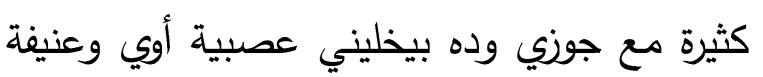
فى كل علاقاتي"، وتقول زوجة أخري:" أنا ديما بحس إني متوترة ومضغوطة من كل شيء حواليه وتوليه

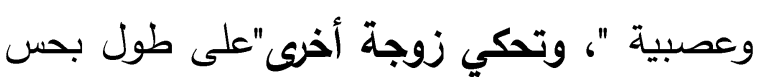

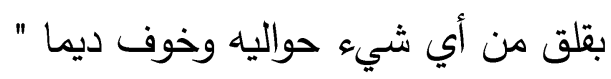
ع - الضغوط الصحية:

كثفت الدراسة الميدانية عن الضغوط الصحية التى تتعرض لها الزوج بسبب سفر

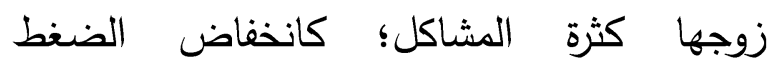
وارتفاعه، والامراض المزمنة، وأمراض خاصة كاضكة

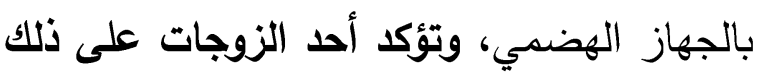

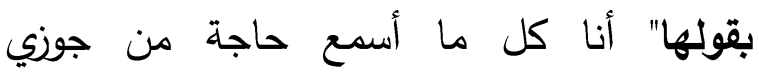
بتعصبني أو تزعلنى هو غيره ضغطي بينزل

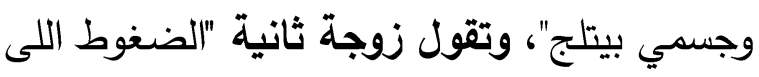
بتقابلني وجوزي بره بتخليني عصبية والقولون عندي بيثد عليه ويتعبني من أقل شيء ومعدتي بوني كلها توجعني وبطني كلها بتبقي هتموتني ومنفوخه

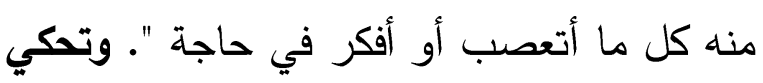

ولاحظت الباحثة أثناء حديثهم حدوث

هيسترية من العياط ونوبة شدية جدا من العييط

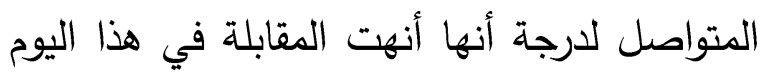
ومحاولة تهائتهم.

وتسرد أخري أن الزوج عندما يأتي من

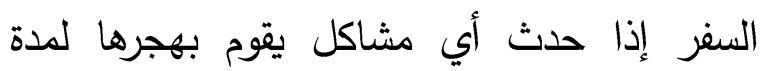
شهر وقد يسافر ولا يتحدث معها، وتؤكد أحد الزوجات على ذلك بقولها" أنا جوزي اتشاكل معايا آخر مرة قبل ميسافر كان نازل شهر دئ

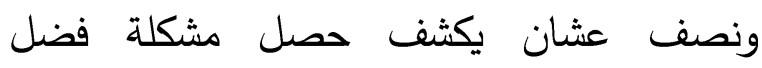
مخاصني ومهاجرني حتي جيت أكلمه وهو مسافر بقي يصدني وميردش"، وتقول أخري"

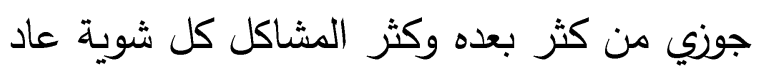
عادي بالنسباله يمشي ويسبني ويبات بره أو يتاخر

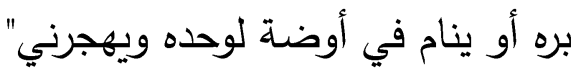
r- الضغوط النفسية:

كثفت الدراسة الميدانية تعرض الزوجات

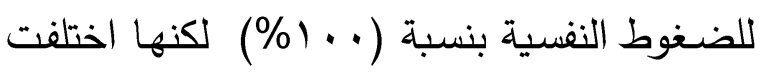

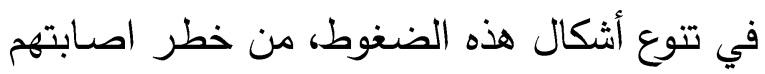

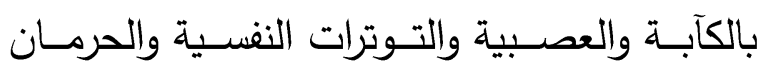

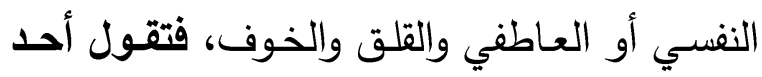

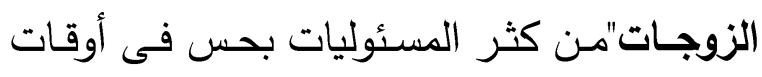

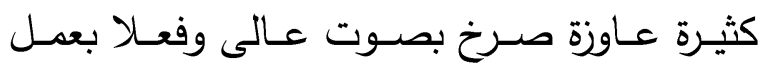

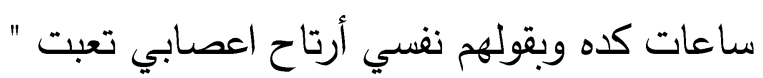

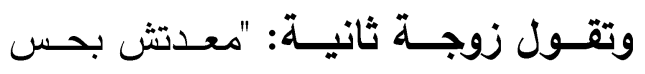

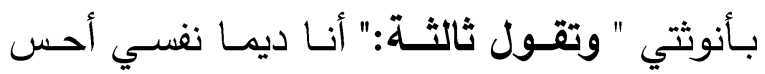

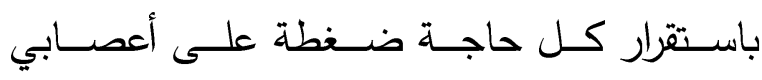
وبتعصب بسرعه"، وروت زوجة رابعة " أنا بحس الحس ديما بحرمان عاطفي وجنسي مبحسش إني متجوزة 
زوجة ثالثة" أنا كل شيء عدت باخده على زوجة ثالثة "انا بيجلي صداع باستمرار بالايام أعصابي عدت ديما أبقي ماشية راسي بتغلى من بيبقي هيموتني من كثر التفكيير والارهاق

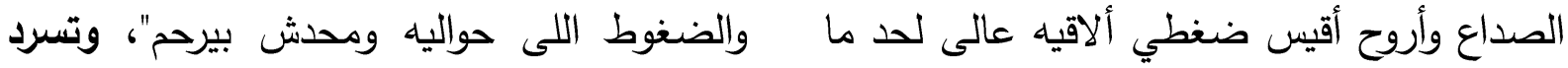

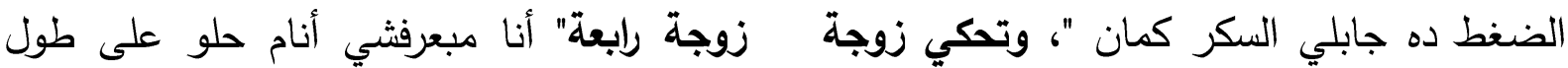

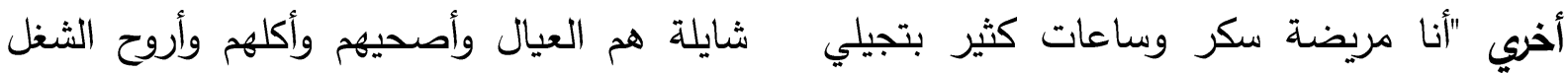

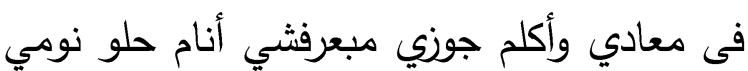

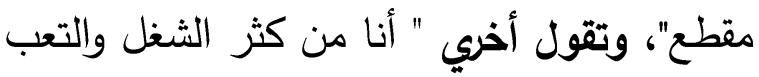

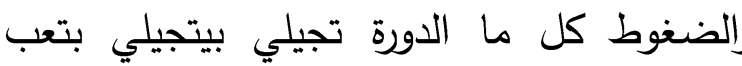
ومغص شديد"، واتتفت أخري معها فى تعب عسر لفر الطمث بقولها "أنا عدت بتعب اوي لما بتجيلي الدورة من كثر منفسيتي والضغوط اللى حواليه وبيجيلي مغص شديد"، وتقول أخري"أنا على طول بحس بهيوط ومعتش عندي طاقة حيلي إتها"، وتقول أخري "أنا على طول عندي دوخة وهبوط عندي بسبب الضغط اللى أنا فيه وعدم الراحة ومعتش بقدر ساعات اعمل الهوا كله كوم ولما الدورة

$$
\text { تجيلي كوم" تعنر سعات }
$$

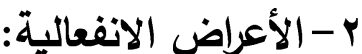

أظهرت الدراسة الديدانية لحالات الدراسة أن ثمة اتفاقا في غالبية حالات الدراسة علي ظهور أعرض انفعالية؛ كالعصبية والانفعال والبكاء والعنف والاحتراق النفسي وتقلب المزاج،

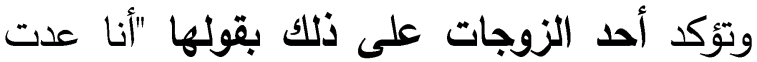
بتعصب من أقل حاجة وبنفعل جدا على العيال واى حد حواليه وساعات كثير جوزي" وتتفق اخري "أنا بتعصب ومن أقل شي وبالذات لمالي أحس إن عليه ضغوط كثيرة "، بينما زوجة أخري تضيف على عصبيتهم انهيارها بالبكاء الثديد بعد الانفعال والعصبية " أنا من كثر الضغوط لفئياء غيبوبة ومحدش معايا لما حد بيضايقني من أهله وأنا في البيت لوحدي أو أزعل معاه شوية"، وتقول

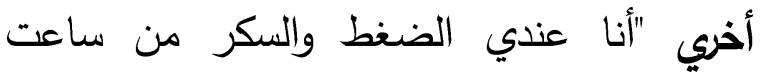
محملت وفضل معايا وبيسبيلي مشاكل صحية كثيرة وجوزي بيقي بعيد ولولا كل شوية بيرن يطمن عليه كان زمانى موت ومحدش حس بيه لأن عيالى في الدروس طول اليوم" لئل

ثانيا: أعراض الضفوط الحياتية للزوجة لانية

\section{الناتجه عن هجرة الزوج للعمل بـالخارج}

كثفت الدراسة الميدانية عن أعراض الضغوط الحياتية للزوجة الناتجة عن هجرة الزوج

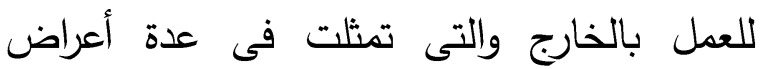
جسدية وانفعالية وذهنية. 1-الأعراض الجسدية :

أنتبت الدراسة ظهور بعض الأعراض : باض الجسدية؛ كالعرق الزائد والتوتر والصداع وعدم الانتظام فى النوم وعسر الطمث وفقدان الطاقة، وعبرت أحد الزوجات عن ذلك بقولها "أنا من كثر الضغوط والمشكل ايدي ورجلي بيعرقو بطريقة صعبة ومن كثر شغل البيت بلاقي جسمي بيعرق بسرعه من كثر الاجهاد والثغل" وتذكر زوجة ثانية"انا من كثر الضغوط والله على طول بيجيلي صداع وكل ما أكثف يقولى يارهاق وانتي ضاغطة نفسك حاولى ترتاحي شوية "، وتحكي 


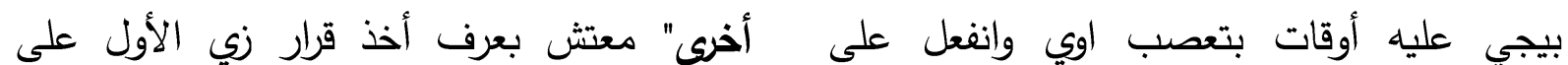

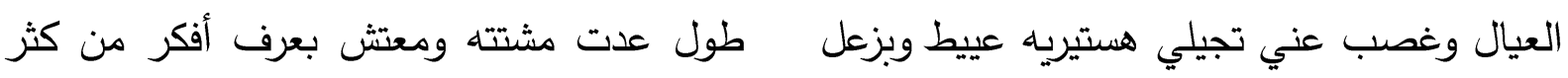

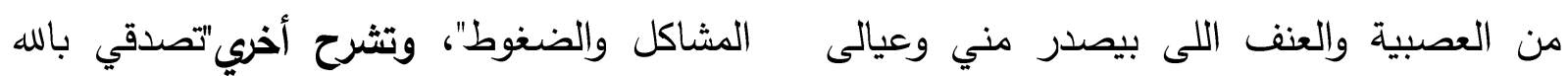

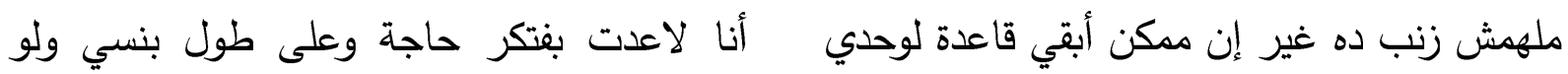

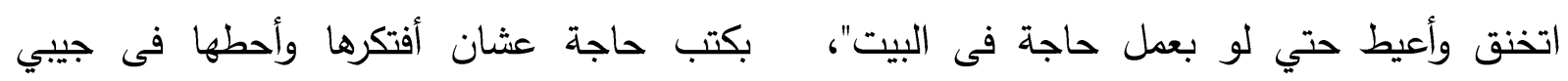

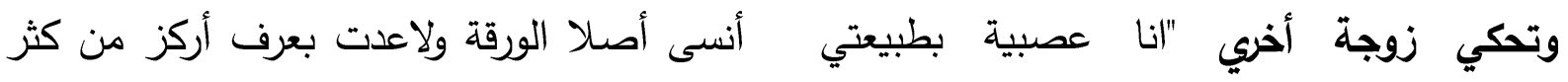

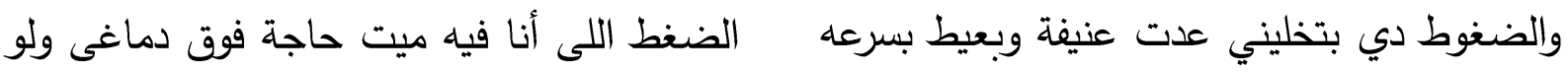

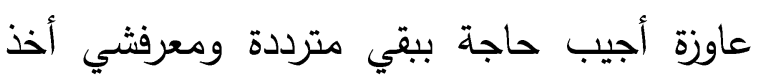
قرار ياجبها ويحصل زي ميحصل يا أحاول أخد الخدان حد معايا وأنا بشتريها وحياتي نفسها معتش قادرة أخد قرار كده كده حلو وحش بيجي فوق دماغك

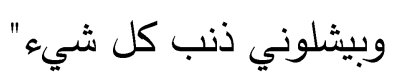

ولاحظت الباحثة عند حديثها مع دابة

المبحوثات أن تلك الأعراض التي تظهر عليهم

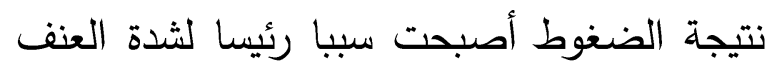
بينهم وبين أزواجهن وعدم تقدير العديد من الأزواج لثدة الضغوط التى يمرون بها وحدوث الصراعات وعدم التفاهم بين الزوجين بسبب طول لهرون

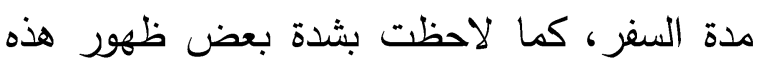

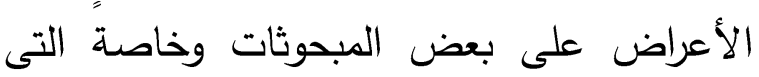
كانت تطول فيه مدة المقابلة برغبتهن، كما لاحفات وفاهنة لاحظت رغبتهن فى الحديث لمدة طويلة وسرعة

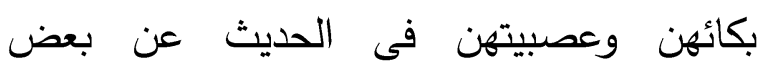
الامور.

ثالثًا : ملامح تفيير الادوار لكل من الزوجين

كثفت الدراسة الميدانية ملامح التغيير

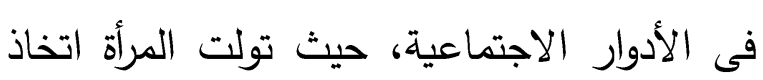

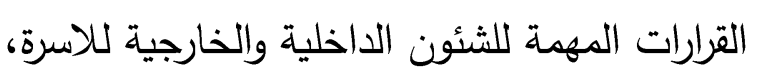

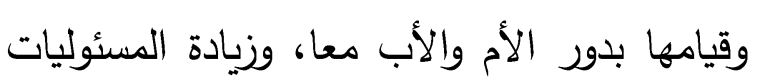

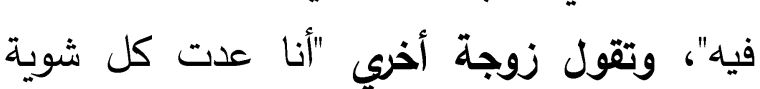
بحال مرة مزاجي يبقي حلو ومرة يبقي وحش فجاة

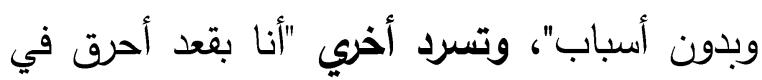
دمي وأعصابي من اللى بشوفه ولاحد بيحس بيه آليه وعدت بعييط كثير من غير سبب واقل حاجة لئو

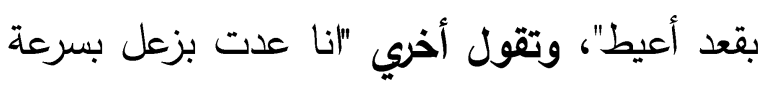

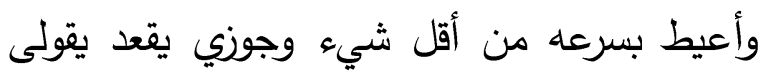
انتي كل حاجة عادت بتزعلك فيه إيه وفى ثانية مزاجي يتقلب واتخنق حتي لو بتكلم مع حد وبكلمه حلو أبقي مش طيقاه"

r-الأعراض المعرفية أو الذهنية:

أوضحت الدراسة الميدانية ظهور بعض الاعزض المنة:

الأعراض المعرفية؛ كالنسيان وعدم التركيز وعدم

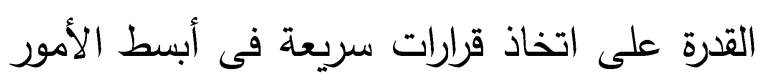
والتردد، وتؤكد على ذلك أحد الزوجات بقولها " أنا عدت على طول بنسي"، وتقول زوجة ثانية

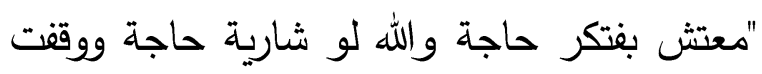
اشتري حاجة تانية ممكن انسي الثنط ومعرفثي أنا نسيتهم فين حتي لو راكبة عربية انسي أنا كان

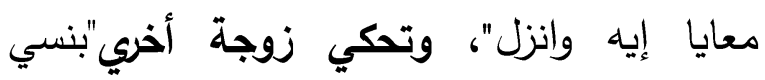
ومعتش بركز خالص في أي حاجة"، وتقول 
اتعودت على سفره كل لما ينزل يحصل مشاكل كثيرة، انا مش عاوزة منه شيء غير الفلوس، إحنا عايشين حياتنا كويس من غيره مش حساه بيقوم باي ادوار حتي ولاده مش عارف يحتويهم زي اي أب، لدرجة إن إبني الكبير اتعرض لحالة نفسية

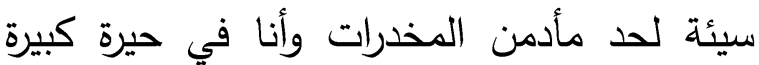
وقلبي بيتقطع عليه وهو مش عاوزة ينزل بيقولى مش عارف فين دور الأب أنا قايمة بحاجات كثيرة معتش قادرة وولادي بيضيعو مني من كثر الضغوط والمسئوليات مسئوليات عمل وأسرة وأهله وهو نفسه بيشيلني همه"

وعبرت زوجة أخري بقولها "مينفعش بئل

الزوجة لوحده ترعي ولادها سفر الزوج ده مشكلة

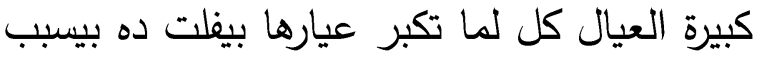
ضغوط كبيرة وبيخليني أقوم بدور الأب مع دوري لياي غير مسئوليات امه اللى برعاها بدله وكل المجاملات لقرايبه واللى حوالينا ولو حد تعب ببقي بجري زي المجنونه ومش معايا حد"، وتقول أخرى "الزوج فى البيت ليه دور كبير خاصة لما يكون

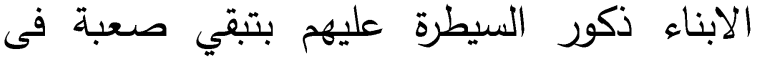
مرحلة المراهقة مهما كن شديدة لازم ابوهم يجي لإعي هلئ

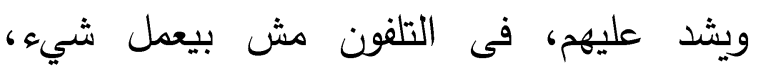
فطبيعي بقوم بدوره جوزي بقي كل دوره انه يجيب فلوس ويتطط عليه بس بالكلام هو واهله"،

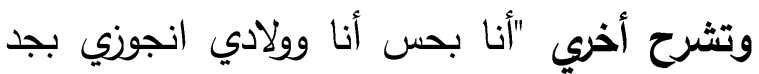
ملوش لازمة غير إنه يجيب فلوس وياريتها بتقضينا انا بشتغل وبصرف قد مرتين وبعمل كل حاجة لولادي كاني قاعدة لوحدي وهو ملوش وجود انا معتش بحبه ينزل من كثر انه ملوش
والأعباء، وعبرت أحد الزوجات عن ذلك بقولها

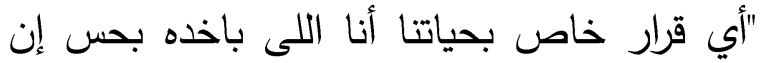

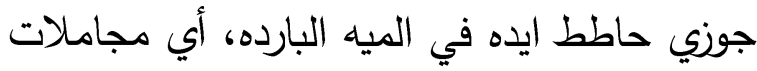
أو أي حاجة أنا اللى بقوم بيها سواء خاصة بيه أو بجوزي أو أهله، أنا بشتري كل شيء وياريت بشتري الحاجة بسهولة لازم بعد مشاكل مع والدته

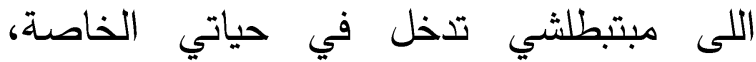
وللأسف عاد معتمد عليه في كل شيء حتي لما بينزل"، وذكرت زوجة ثانية " أي حاجة أنا اللى

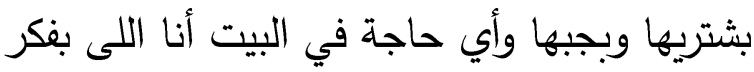

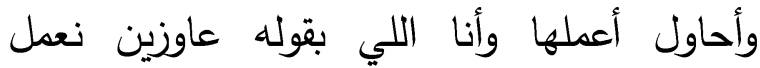
والمفروض نعمل ونسوي واقنعه عثان تتعمل بحس إني كل حاجة فوق دماغى لما تعبت، نفسي يبقي موجود عشان يشيل عني شوية تصدقي بالله أنا وصلت معايا لدرجة إنى بشتغل حلاق للعيال في البيت عشان متعرضشي لمضايقة من حلاق أو أى راجل رخم والعيال صغيرة مينفعي تتزل لوحدها وانا مليش اخوات صبيان ولا اخواته موجودين حتي كلهم مسافرين"، وتقول زوجة ثالثة "أنا اللى بعمل كل شيء سواء المفروض أنا أقوم بيها أو جوزي يقوم بيها سواء

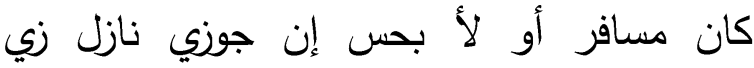
الضيف مش عاوز يعمل شيء" وتضيف زوجة معاناتها من ضعف الصلة بينها وبين الزوج وأيضا الابناء بسبب مده السفر وعدم إظهار أي دور لهم سوي الماديات وأنهم أصبحو إسم في مجرد شهادات ميلاد فقط،

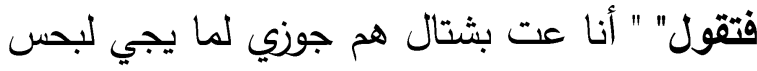
ان جيلنا ضيف ثقيل على قلبي انا والعيال، 
وهو كمان بدأ يتغير ومعتش بحس إن متجوزة لما بيجي ينزل معتمد عليه بقي في إن أشتري كل

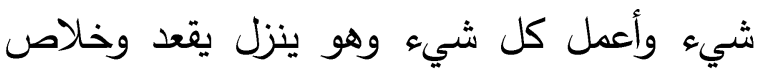

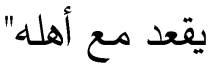

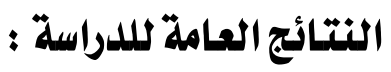

1-كثفت الدراسة عن أنواع الضغوط الحياتية للزوجة الناتجة عن هجرة الزوج والتى تمثلت في الضغوط الاجتماعية؛ كالتفكك

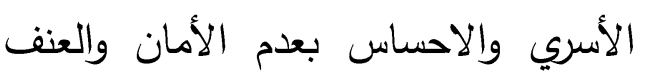
الأسري وضغوط العمل والخيانة الزوجة،

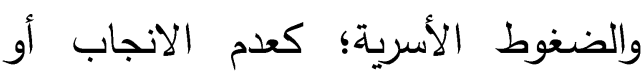
انضمام عضو جليد كحمل غير مرغوب

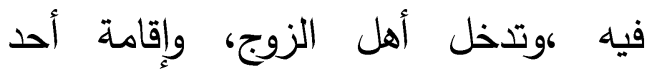

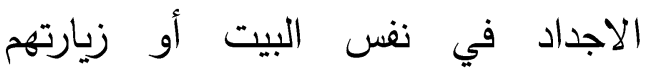
باستمرار وعدم احترام خصوصيات الزوجة بتدخلهم المتزايد ومحاولة فرض السيطرة،

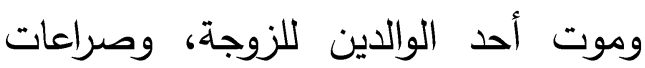
بين الزوجين، والضغوط النفسية؛ كالاصابة بحالات الاكتئاب والعصبية والتوتر والحرمان النفسي والعاطقي والقلق والخوف، والضغوط الصحية؛ كانخفاض

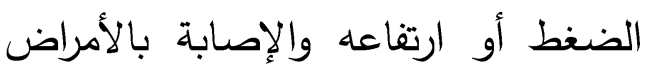
المزمنة وأمراض خاصة بالجهاز الهضمي.

r-كثفت الدراسة عن أعراض الضغوط الحياتية للزوجة الناتجة عن هجرة الزوج تمثلت فى أعراض جسدية؛ كالعرق الزائد، والتوتر، والصداع، وعدم انتظام في النوم،

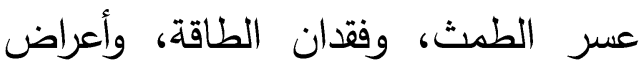

وجود في حياتتا غير المشاكل حتي ولادي برده معدوش بيحبوه ينزل عشان المشاكل اللى بتحصل واللى بيشوفوه" وتقول اخري" أنا مش حاسة إن متجوزة أصلا أدوار ايه معييش عيال وجوزي كل ماكلمه سيبي شغلك وتعالى اقعدي أنا مش نازل والاتصالات بينا قلت الحاجة الوحيدة اللى بيقوم بيها ومش على طول انه ممكن يبعتلى مصروف ليه وساعات مش بيكفيني زي اللى بينقطني اما دوي كزوج فين مفيش لو حصلي حاجة من اهلة ولا كانه موجود لو احتاجت شيء ولا كانه موجود لو تعبانة او نفسيتي تعبانة معرفشي اكلمه زي الأول السفر والغربة خلت معتش حياة بين

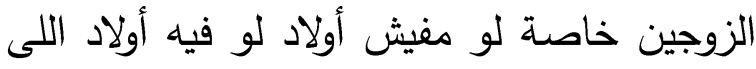
بيتثال كل شيء الزوجة برده"

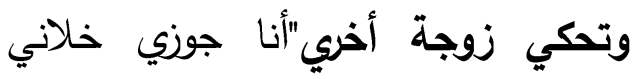
سبت شغلى خدت أجازة طويلة وبتاجر في اللبس أنس جري من البيت عثان ولادي وأنا طبعا بودي وأجيب الددرسة أو تعبان عيل بشتال وأجري وأروح لوالدته اخدمها وأقعد اكلمه طول اليوم هو بصراحة بيبعتلى كل فلوسه اللى بيقبضها حتي لما جينا

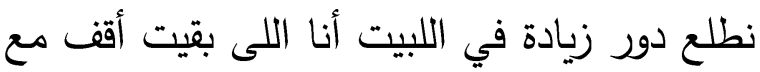

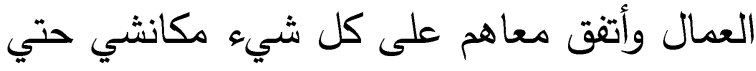

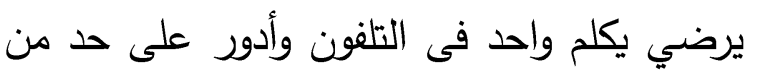

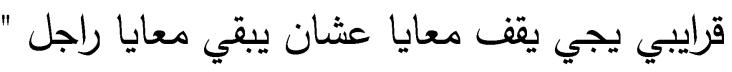
وتقول أخري" انا قاعدة في بيت أبويا كل أدوارنا مكالمات تلفون وقلت عن الأول ومبعرفثي لائ عنه شيء حتي أبسط حقوقي مش بلاقيها ومطالب مني أروح لأهله وكل لما أروح أودهم يبهدلوني من غيرتهم لحد مقطعت العلاقة بينهم 
(1) ايمان الحسيني عطية الحسيني: تقييم خدمات مؤسسات مؤسسات رعاية الطفولة والنهوض بالاسرة في التخفيف من حدة الضغوط من حدة الضغوط الحياتية للمراة دراسة مطبقة علي مؤسسات رعاية الطفولة والنهوض بالاسرة بمحافظة الدقهلية، رسالة ماجستير (غير منشورة )، كلية الخدمة الاجتماعية،

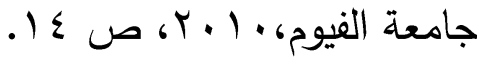
سناء حمح هارون: الضغوط الحياتية لدي الزوجات العاملات وعلاقتها بالاكتئاب، رسالة ماجستير (غير منشورة)، كلية الاداب،

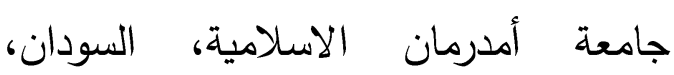

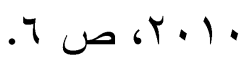
عبد العزيز فهمي النوجي: الممارسة العامة فى الخدمات الاجتماعية عملية لعل المشكلات ضمن اطار نسقي ايكولوجي (الكتاب الثالث)، الطبعه الثالثة، بدون دار

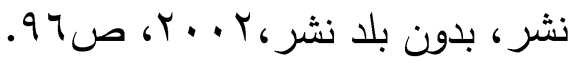
https://mawdoo3.com مجلة آفاق الهجرة: مركز السودان للدراسة الهجرة والتنمية السكانية بمركز جهاز شئون

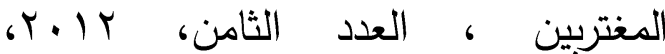

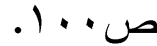
سوزان أحمد حسن : تأثير الهجرة على مستويات الإنجاب (دراسة لعينة من مهاجرى بيئات مختلفة)،رسالة دكتوراه، قسم العلوم الانسانية والبيئية، معهد الدراسات والبحوث البيئية، جامعة عين شمس، 10 ـ ب.
انفعالية؛ كالعصبية والانفعال والبكاء والعنف والاحتراق النفسي وتقلب فى المزاج، وأعراض ذهنية؛ كالنسيان وعدم التركيز والتردد في اتخاذ القرار . r- أظهرت الدراسة ملامح تغيير الأدوار بين الزوجين فى دور الزوج اقتصر على الجانب المادي وتوفير الماديات، أما الزوجة فتمثل دورها في اتخاذ القرارات

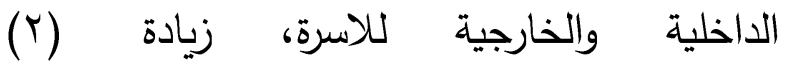
المسئوليات الطبيعية للزوجة والقيام بدور الأب مما جعل الزوجة تكون لديها سيطرة أعلى من الاب، الالتزام برعاية وتربية الابناء رعاية كاملة، الالتزام برعاية أهل

الزوج أيضا، القيام بالمجاملات والإحلال (r) مكان الزوج في أي شيء يخصه.

\section{توصيات الدراسة :}

أولاً: العمل على زيادة وعي الشباب والفتيات المقبلين علي الزواج من خلال مكاتب التوجيه والاستشارات الأسرية والجمعيات ومجالس مرون

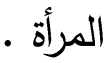

ثانيا: استمرار بذل الجهود علي كافة المستويات لتوعية الزوجين وإعطاء دبلومات خاصة بالحياة الزوجية، لكيفية مواجهة المشاكل الزوجية والضغوط الناتجة عنها. ثالثا: العمل على زيادة الوعي للزوجين في الريف، لتغيير العادات والتقاليد الخاطئة التى تسبب الضغوط الحياتية ليس فقط للزوجة وانما • الزوجين 


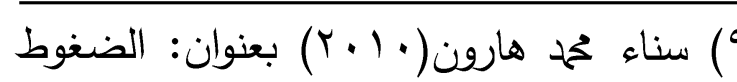

الحياتية لدي الزوجات العاملات وعلاقتها

$$
\text { بالاكتئاب، مرجع سبق ذكره. }
$$

(10) keith Stephanie: stress and social support in mother of children, clifornia state university, long beach, 2004.

( 11) Suzanne quellete kabasa: personnailty and resources in life stress resistance, the university of mantba,canda, 1999.

(12) Ronald Ganellen and Pual Blanty:Hardiness and Sicialsupport of the Effects of life stress,New York University, 1999
عزة محمود أمين: الهجرة الخارجية وأثرها (V)

على الأسرة للريفيين (دراسة ميدانية لعينة من الأسر بقريه طبهار بمحافظة الفيوم

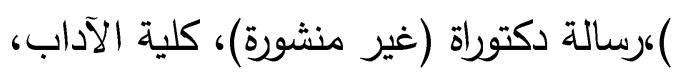

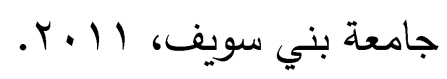

شيرين مصطفي رزق دعدور: الآثار

السوسيولوجية لهجرة الآباء على الأسرة المصرية دراسة ميدانية فى مدينة المنصورة، رسالة ماجستير (غير منشورة)، قدم

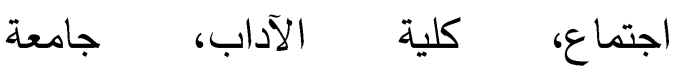

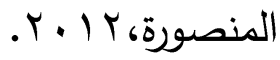

